\title{
PARADIGMA PERAN DEKAN IDEAL: The Dove, The Dragon, dan The Diplomat dalam Membangun Fakultas yang Kuat
}

\author{
Oleh: Abdul Kadir*
}

\begin{abstract}
The management of a faculty should encourage staff participation for a change. A decreasing trend of government financial support for higher education pushes a faculty to be more efficient in financial plan. In line with this, a good faculty should develop harmonious relationship internally and externally. Such is a strong collaboration which may lead to positive process, input, output and outcome. To get a maximum outcome, there are at least five aspects to strengthen; strengthening of steering core, building network, developing resources, diversifying funding base, and developing a culture of entrepreneurship. To achieve these aspects, a dean should play roles as a dove, a dragon and as a diplomat.
\end{abstract}

KEYWORDS: Pengelolaan fakultas, transformasi, peran dekan

PERNYATAAN yang sangat menarik yang diibaratkan oleh Tucker bahwa seorang dekan fakultas setidaknya harus dapat berperan atau memposisikan dirinya dalam tiga model peran. Ketiga peran tersebut adalah the dove of peace, the dragon, dan the diplomat. ${ }^{1}$

Pada saat tertentu Dekan hendaknya sanggup berperan sebagai merpati perdamaian (the dove of peace) ketika dekan aktif menjadi penengah tatkala terjadi konflik internal di lingkungan fakultas. Disinilah peran dekan yang adil dapat melihat hal-hal apa yang kurang untuk dilengkapi. Potensi yang sesungguhnya ada namun belum dikembangkan secara maksimal agar dapat didayagunakan. Mungkin juga hal-hal yang tidak dilaksanakan dengan baik di kalangan departemen, jurusan, dan mahasiswanya agar dilaksanakan secara efektif dengan asupan inovasi yang memadai dan berkelanjutan.

Pada saat lain, dekan dapat berperan sebagai seekor naga (the dragon) yang harus mampu mengarahkan ke arah yang lebih efektif, efisien, dan

*Kandidat doktor pada Program Pascasarjana UNJ, Prodi Manajemen Pendidikan, ini adalah guru sekaligus Wakil Kepala Sekolah SMP Negeri 15 Mataram dan Dosen Luar Biasa pada FKIP Universitas Muhammadiyah Mataram. 
etis dari tuntutan gerak maju kekuatan internal maupun eksternal yang berpotensi mengancam sistem nilai, kestabilan keuangan, maupun integritas dari unit-unit akademik yang sudah berlaku dengan baik. Dengan kata lain hanya the dragon yang dapat melawannya.

Sementara itu, dekan juga pada saat lain berperan sebagai seorang diplomat (the diplomat). Hanya seorang dekan yang "diplomat" yang dapat membawa dan menyemangati kehidupan fakultas agar tetap tegar berdiri dari berbagai kritik baik dari dalam maupun dari luar fakultas yang tidak jarang hanya bisa melihat kesalahan saja. Menghadirkan kritik-kritik pedas tanpa memberikan dukungan solusi yang memadai. Hanya melempar bola api masalah, tanpa menawarkan solusi yang arif. ${ }^{2}$

Memang, tidak dapat dipungkiri bahwa kunci keberhasilan suatu fakultas dalam sebuah universitas pada hakikatnya terletak pada efisiensi dan efektivitas kepemimpinan seorang Dekan. Keberhasilan fakultas adalah keberhasilan Dekan dan keberhasilan Dekan adalah keberhasilan fakultas. Banyak pemikir pendidikan tinggi yang mengklaim bahwa roh sebuah universitas adalah fakultas. Bilamana fakultas mampu mengenal kondisinya saat ini, menetapkan target yang ingin dicapai dalam jangka waktu tertentu, mampu mengatasi kultur internal maupun eksternal, serta memperluas akses yang diiringi dengan akuntabilitas sepanjang proses tersebut, maka cita-cita memiliki sebuah fakultas yang kuat bukanlah sesuatu yang tidak mungkin.

Ada juga pendapat yang mengatakan, the spirit of faculty is the spirit of the dean. Idealnya setiap fakultas memiliki spirit atau nilai-nilai tertentu, misalnya disiplin diri, tanggung jawab, kebersamaan, dan keterbukaan. Spirit dan nilai-nilai tersebut akan mewarnai pembentukan struktur organisasi fakultas, penyusunan deskripsi tugas, sistem dan prosedur kerja fakultas, kebijakan dan aturan-aturan fakultas, upaya perbaikan berkelanjutan, pemanfaatan resources yang maksimal, dan tata tertib melekat yang dapat melejitkan sebuah fakultas yang kuat. Semua tanggung jawab itu bertengger di bahu kokoh seorang dekan.

Pengaturan institusi fakultas dalam merumuskan visi, misi dan program kerja yang akan menjadi landasan berpijaknya mengacu pada seperangkat peraturan nasional seperti UU 20/2003 tentang Sisdiknas ${ }^{3}$ dan PP 60/1999 tentang Pendidikan Tinggi. ${ }^{4}$ Pengaturan tentang status dan kedudukan fakultas serta dekan, khususnya diatur pada Bab I tentang Ketentuan Umum, utamanya pasal 1 butir 13 tentang fakultas dan butir 14 pada pasal yang sama tentang dekan. Selain itu, secara rinci dijelaskan pada pasal 30 (ayat 2) tentang kedudukan fakultas, dan pasal 45 s.d pasal 
48 yang secara detail membahas tentang organisasi dan gerak langkah fakultas. Rujukan selanjutnya adalah Statuta Universitas yang di dalamnya memuat seperangkat mandat tentang kedudukan fakultas.

Bertolak dari konsep tersebut, maka fenomena tentang paradigma, proses dan praktik manajemen pendidikan tinggi pada tingkat fakultas memang perlu dipahami. Hal ini menjadi penting mengingat pada tingkat inilah universitas dapat mengandalkan fakultas, jurusan dan program studi sebagai steering core atau ujung tombak akademik terdepan. Dengan demikian, memahami manajemen fakultas dalam koridor yang benar dapat diasumsikan berarti memahami gerak dinamika universitas sebagai sebuah sistem. Karena, fakultas merupakan sebuah subsistem paling penting dari suprasistem universitas dengan berbagai fenomenanya.

\section{RUANG LINGKUP PENGELOLAAN FAKULTAS}

Ruang lingkup pengelolaan fakultas sangat dipengaruhi oleh setiap keputusan dekan. Itulah sebabnya mengapa otonomi sebuah fakultas itu sama pentingnya dengan pembentukan fakultas itu sendiri. Seorang dekan hendaknya memahami bahwa ia sesungguhnya memiliki otoritas yang cukup dalam membuat keputusan penting yang rasional. Namun seorang dekan yang arif hendaknya lebih memahami lagi bahwa ia terhambat oleh rasionalitasnya yang terbatas (bounded rationality) sebagaimana halnya individu-individu lain. Demikian pula individu-individu yang merupakan komponen pendukung fakultas, juga memiliki otoritas sebesar mandat yang diterimanya. Individu tersebut juga memiliki otoritas dalam membuat keputusan. Untuk itu dibutuhkan kesadaran yang cukup bagi setiap individu bahwa keputusan yang dibuatnya yang berkaitan dengan fakultas merupakan keputusan organisasi, dan bukan keputusan individu semata yang cepat atau lambat akan membawa dampak bagi fakultas.

Dapat dicontohkan dalam tulisan yaitu ketika seorang dosen secara pribadi memutuskan menggunakan instrumen evaluasi yang sama dalam beberapa kali ujian di tahun berbeda, maka tunggulah saatnya organisasi yang melaksanakan ujian tersebut akan mendapatkan sorotan. Sorotan tajam akan diterima baik dari komponen internal organisasi maupun eksternal organisasi tentang validitas instrumen yang digunakan. Hal ini bukan tidak mungkin akan membawa dampak bagi ketidakpercayaan konsumen pada komitmen evaluasi organisasi secara keseluruhan yang berdampak pada image yang buruk organisasi tersebut. 


\section{HUBUNGAN INTERNAL DAN EKSTERNAL DALAM PENGELOLAAN FAKULTAS}

Pasal 46 Peraturan Pemerintah RI Nomor 60 tahun 1999 mengemukakan bahwa: (1) Fakultas dipimpin oleh Dekan dan dibantu oleh Pembantu Dekan, yang pada dasarnya terdiri atas Pembantu Dekan bidang Akademik, Pembantu Dekan bidang Administrasi Umum dan Pembantu Dekan bidang Kemahasiswaan. (2) Dekan memimpin penyelenggaraan pendidikan, penelitian, dan pengabdian kepada masyarakat, membina tenaga kependidikan, mahasiswa, tenaga administrasi dan administrasi fakultas, serta bertanggung jawab kepada Rektor. (3) Pembantu Dekan bertanggung jawab kepada Dekan.

Dalam melaksanakan tugas-tugasnya seorang dekan bertanggung jawab dalam menciptakan atmosfir kerja kondusif di tempat yang menjadi tanggung jawabnya. Untuk tujuan itu, dekan hendaknya mampu menjalin hubungan kerja harmonis baik ke dalam maupun ke luar fakultas.

\section{Hubungan ke dalam (Internal relationships)}

Hubungan ke dalam diantaranya mencakup hubungan-hubungan dengan unit-unit akademik maupun staf pendukung nonakademik, diantaranya: (a) hubungan sinergis dengan para Pembantu Dekan, Jurusan dan bawahannya, Ketua Program Studi dan bawahannya, dosen, mahasiswa dan unsur-unsur akademik lainnya. (b) Dekan juga beperan cukup signifikan dalam menciptakan kondisi kerja yang baik antar staf dengan staf lainnya dalam lingkungan fakultas (man to man), staf dengan sarana prasarana (man to tools/machine). (c) Menegakkan aturan-aturan dan disiplin fakultas sebagaimana yang telah disepakati bersama, memberikan motivasi yang proporsional sesuai kebutuhan staf, dan menghindari munculnya konflik internal yang tentu saja akan mempengaruhi kinerja staf dalam upaya mencapai tujuan fakultas.

Kemampuan dekan mendayagunakan segala potensi yang ada dari dalam sebagai motor penggerak pencapaian tujuan fakultas merupakan faktor terpenting dalam pengelolaan fakultas. Dekan hendaknya jeli melihat setiap kesempatan untuk melejitkan proses, produk dan output fakultas melalui kolaborasi yang selaras dan harmonis. Hal ini sejalan dengan pendapat Tucker ${ }^{5}$ bahwa ...quite often there exists a lack of understanding, sometimes even a sense of mistrust, between the academic and its nonacademic support staff. ...it relates to dean's interaction with nonacademic personnel staff, puchasing, travel, maintenance, and even campus security. 


\section{Hubungan Keluar (External Relationships)}

Dekan bukanlah penjaga Fakultas. Seorang dekan yang dibutuhkan pada era persaingan kualitas universitas saat sekarang ini adalah figur pimpinan fakultas yang energik, inovatif dan memiliki hubungan baik dengan berbagai pihak termasuk unsur-unsur dari luar yang relevan dengan pencapaian tujuan fakultas. Unsur-unsur dari luar tersebut misalnya yayasan, staf universitas di luar fakultas, mulai dari rektor, pembantu rektor, kepala departemen, dekan dari fakultas lain, dan lembaga-lembaga lain yang mendukung tegak berdirinya universitas bahkan sampai pada penjaga kantin kampus. Sedangkan unsur-unsur lain seperti masyarakat, orang tua mahasiswa, media massa, pemerintah, alumni, LSM, dunia usaha dan dunia industri, agen perjalanan, lembaga pendidikan lain dan bahkan penjaga malam.

Aspek yang terpenting adalah unsur-unsur pendukung tersebut dapat memberikan kontribusi terhadap fakultas, sehingga fakultas dapat melayani mahasiswa lebih baik dan produktif. Selain itu, dekan juga hendaknya memiliki jiwa enterpreneur yang baik sehingga terjalin hubungan-hubungan yang saling menguntungkan. ${ }^{6}$

\section{PENGELOLAAN FAKULTAS DALAM SITUASI SULIT MELALUI EN- TERPRENEURSHIP}

Fenomena yang tengah dihadapi fakultas saat ini memang sangat kompleks dan dilematis. Wajar saja bila Bill Reading mengatakan dan bahkan menulis "The University in Ruins."7 Fakultas sebagaimana universitas menghadapi krisis ganda (doubled crisis). Di satu pihak fakultas menghadapi tuntutan pasar (market force) yang demikian kuat dan di pihak lain banyak fakultas yang lamban merespons (innertia/response imbalance) terhadap berbagai perubahan yang terjadi khususnya banyak fakultas pada perguruan tinggi di Indonesia.

Semakin kuatnya tekanan yang berasal dari luar dan performa yang belum maksimal dari dalam, menyebabkan fakultas harus berusaha semaksimal mungkin agar bisa tetap kuat. Rising demand yang bahkan beberapa ahli mengatakan demand overloaded dari luar misalnya social responsibility, world of works, link and match, among faculties or university competitiveness, dan bahkan university ranks membelit pendidikan tinggi. Sementara itu, performa dari dalam seperti resistance on management, lemahnya inovasi, scarcity of resources, leadership, dan atau belum berfungsinya semua komponen membawa kesulitan tersendiri bagi perkembangan fakultas yang berkualitas. Kondisi ini semakin diperparah oleh anggaran untuk 
pendidikan tinggi yang semakin kecil sementara tuntutan masyarakat akan pendidikan murah dan berkualitas semakin kuat. ${ }^{8}$

Menghadapi fenomena tersebut, dalam prosesnya maka fakultas harus segera melakukan transformasi. Hal-hal yang perlu mendapatkan perhatian diantaranya adalah: ${ }^{9}$

1. Memiliki steering core yang kuat misalnya melalui otonomi. Fakultas perlu memiliki otonomi yang luas baik pada tataran perguruan tinggi, fakultas, jurusan maupun lembaga-lembaga yang ada di dalamnya untuk menentukan arah perkembangan mereka sendiri sesuai dengan tujuan fakultas. Pada dasarnya semua komponen dalam fakultas itu functioning. Prinsip-prinsip seperti empowering the staff perlu segera dilakukan. Permasalahan yang dihadapi adalah kebanyakan komponen itu tidak tahu harus berbuat apa atau siapa melakukan apa. Untuk itu perlu komunikasi yang baik, perencanaan yang matang dan komitmen yang tinggi untuk melakukan tugas-tugas tersebut. ${ }^{10}$

2. Memperluas developmental periphery yaitu melalui berbagai langkah inovatif. Namun agar hal ini disa dijalankan, fakultas perlu mengenal kapabilitas dirinya (institutional capabilities) melalui penilaian diri yang benar. Di mana posisinya saat ini, kemana arah yang ingin dituju yaitu dengan menetapkan tujuan akhir, berapa banyak resource yang dibutuhkan, dan langkah-langkah apa yang akan dilakukan untuk mencapai tujuan tersebut yang dibarengi dengan proses akuntabilitas yang berkelanjutan. Dalam proses ini fakultas perlu menetapkan benchmarking, sehingga mengetahui ketercapaian lompatan-lompatan yang dilakukan, apakah perlu leverage (pengungkit) atau melanjutkan lompatan ke titik berikutnya.

3. Sebagai konsekuensi dari kebijakan-kebijakan yang diambil maka perlu dilakukan diversified funding base (diversifikasi pembiayaan). Sebagaimana Shattock mengemukakan bahwa "higher education needs finnancial support to enhance the transformation." Patron lama yang hanya mengharapkan pembiayaan yang berasal dari subsidi pemerintah dan iuran mahasiswa perlu segera diantisipasi dengan berbagai cara misalnya melalui enterpreneurial activities dan diversification source of funding.

4. Guna sukses meningkatkan peran ketiga aspek di atas, maka partisipasi dari berbagai unsur dalam diri universitas, fakultas atau jurusan sangat perlu (academic heartland stimulating). Partisipasi tersebut bukan hanya diperlukan ketika lembaga sedang dalam situasi turbulensi, akan tetapi dibutuhkan sepanjang perjalanan organisasi baik selama proses perencanaan, implementasi dan evaluasi serta feedback-nya. Partisipasi ini bisa 
ditingkatkan dalam semua level baik di tingkat fakultas maupun jurusan. Fakultas sesungguhnya bisa menjadi strategic business unit. Bagaimana unit-unit tersebut merancang, berjuang, dan siap menerima third-stream income sesuai dengan sebesar upaya inovatif apa yang telah mereka masing-masing lakukan. Dilihat dari peningkatan kualitas misalnya yaitu dengan meningkatkan kualitas dan kuantitas riset, teaching dan lifelong learning, akreditasi, mengadopsi, dan mengembangkan teknologi baru serta pemberdayaan staff akademik. ${ }^{11}$

5. Keberhasilan juga dapat diraih melalui penggalakkan budaya enterpreneurial yang memungkinkan perubahan bagi lembaga. Sebab bukan tidak mungkin ada beberapa komponen yang tidak memahami values dari pada upaya transformasi yang dihajadkan. Hal ini menjadi penting mengingat values or beliefs tersebut memungkinkan akan menumbuhkan pengembangan pada elemen-elemen lainnya. Dengan demikian, perspektif institusi sangat dibutuhkan.

Bilamana proses telah dilaksanakan dengan baik maka keluarannya pun dapat diharapkan menjadi baik pula. Memang masyarakat hanya melihat aspek keluarannya saja tanpa mau perduli bagaimana prosesnya yang demikian rumit dan dilematis. Fakta banyak "penganggur terdidik" selalu menjadi indikator kualitas lulusan. Oleh sebab itu, keluaran tersebut dapat ditingkatkan kualitasnya baik melalui short-term solution maupun long-term effect yang diprogramkan secara terencana oleh universitas yang tentu saja harus melibatkan fakultas. Dalam hal ini, fakultas harus tetap konsen pada penciptaan knowledge society yang hanya dapat dilakukan dalam atmosfir academic excellent sehingga output kelak dapat berbicara banyak di lapangan. Poin terpenting di sini bahwa hanya fakultas yang kuat yang dapat melaksanakannya dengan sukses, efektif dan efisien.

\section{BERGUMUL DENGAN BUDAYA DALAM PENGELOLAAN FAKUL- TAS}

Budaya organisasi (korporat) saat ini memang sangat kuat dipengaruhi oleh budaya yang berlaku secara makro. Demikian pula di lingkungan perguruan tinggi. Pada lingkungan fakultas sepertinya utuh berlaku sistem cybernetic dimana prosesnya mengarah pada tujuan yang telah ditetapkan. Meskipun ada halangan tapi akan cenderung mencari jalan untuk menyesuaikan keadaan agar dapat tetap menuju pada arah yang telah ditetapkan. Sesungguhnya budaya ini merupakan potensi yang bila dikembangkan akan menghasilkan output yang bagus, setidaknya identitas dan kontinuitas lembaga tersebut.12 
Permasalahannya adalah faktor individu yang berpotensi membentuk budaya fakultas. Individu-individu dengan otoritas yang dimilikinya menggunakan budaya untuk mengekspresikan kepercayaan, perasaan, ide, informasi, dan sebagainya sesuai dengan keyakinan mereka sebatas rasional yang dimilikinya. Budaya juga merupakan suatu pernyataan keseimbangan timbal balik. Di dalamnya selalu ada yang memimpin dan dipimpin, yang berkerah biru dan kerah putih, bahkan ada yang empunya dan yang bekerja. ${ }^{13}$ Dalam mewujudkan good corporate governance diharapkan ada kesadaran yang besar akan nilai. Nilai tertinggi dalam budaya korporate adalah taken for granted (dianggap sudah semestinya demikian) sehingga memang lebih dari sekedar kebiasaan yang tidak terasa, yang mampu memacu kreativitas, seni, teknologi, artefak dan ciptaan lainnya dalam bekerja dan berbuat.

Bilamana ditemukan gejala budaya yang cenderung merugikan maka yang dapat dilakukan adalah bahwa setiap individu secara kolektif harus:

1. Berkaca pada kapasitas intitusi. Pertanyaan seperti "where do us?" sangat penting bagi organisasi ketika hendak melihat kedalaman dirinya. Itulah sebabnya sistem evaluasi diri itu menjadi sangat vital sifatnya, sehingga fakultas dapat mengetahui dengan pasti dari mana harus berangkat (starting point), sekali melompat sampai di mana (benchmark dan benchmarking), dan berapa kali lompatan seharusnya agar sampai ke tujuan dengan selamat. Kapasitas institusi adalah sebutan lain dari pada to move forward. Setiap yang dilihat dan dikenali khususnya budaya organisasi hendaknya "siap" mengantar fakultas mencapai tujuannya.

2. Menetapkan kualitas yang ingin dicapai. Dalam hal ini perlu dielaborasi kualitas tersebut baik quality in fact maupun quality in perception. Kualitas adalah guiding principles di mana kualitas ini menentukan apa yang harus dilakukan oleh fakultas (What should the faculty do?). Untuk itu digunakan berbagai alat ukur seperti Quality Control, Quality Assurance, Total Quality Management, dan Quality Improvement. ${ }^{14}$

3. Melihat relevansi agar dapat tetap survive dan eksis yaitu melihat relevansi budaya yang ditunjukkan individu dengan visi organisasi yang telah ditetapkan. Jadi perlu ada justifikasi untuk itu agar dapat tetap eksis. Salah satu solusi adalah multi-stage empowerment (pemberdayaan bertingkat). Seluruh individu hendaknya berpikir, berbuat dan berinovasi yang searah dan mendukung pencapaian visi fakultas. ${ }^{15}$

Menangani budaya dalam fakultas memang tidak sekali jadi. Penanganan ini berlangsung terus-menerus dan harus selalu menunjukkan peningkatan. Dengan demikian pondasi manajemen harus kuat dan bertahan terhadap berbagai persoalan, khususnya yang berkaitan dengan budaya. 
Bilamana berbagai upaya tersebut tidak juga berhasil atau tetap jalan di tempat (hukum paradox= point of deminishing return) sementara sudah banyak resource yang digunakan, kemungkinan sudah terjadi kejenuhan (saturate). Maka untuk tetap resistance atau eksis maka perlu dilakukan diversifikasi.

Sebagai contoh: agar fakultas dapat mengejar kualitas seperti pendidikan di luar negeri, maka perlu dikembangkan budaya akademik. Budaya akademik tentu saja merupakan bagian penting fakultas di dalam mencapai mutu akademis yang sangat baik, maka sangat diperlukan budaya akademis di kalangan fakultas dimaksud. Untuk maksud tersebut maka diperlukan peningkatan: ${ }^{16}$ (1) Pengembangan SDM (Dosen, Karyawan, dan Mahasiswa). (2) Pengembangan infrastruktur pendidikan (ruang kuliah, laboratorium, ICT, perpustakaan dan sarana prasarana lain pendukung pendidikan yang berbasis kebutuhan). (3) Pengembangan kinerja civitas akademika (dosen, karyawan, mahasiswa). Pengembangan manajemen berbasis kepuasan pelanggan). (4) Peningkatan kualitas pembelajaran. (5) Peningkatan lingkungan dan budaya akademik. (6) Tersedia penjaminan mutu. (7) Tersedia infrastruktur pendidikan (kelas, ruang diskusi, seminar, ruang dosen, ruang pimpinan dan sebagainya). (8) Terselenggara forum diskusi, seminar dan workshop. (9) Terselenggara tradisi akademik berbasis kebutuhan mahasiswa (pembelajaran berbasis kebutuhan, seperti program bahasa asing, ketrampilan komputer dan sebagainya). (10) Terselenggara tradisi penulisan ilmiah baik berbasis riset lapangan atau pemikiran. (11) Terselenggara eksperimentasi pengembangan masyarakat. (12) Dihasilkan dosen yang memiliki kapabilitas. (13) Dihasilkan karya tulis ilmiah melalui jurnal, koran, majalah dan buku). (14) Dihasilkan karya ilmiah berupa research report yang outstanding. (15) Dihasilkan output dan outcome pendidikan yang memadai.

Melalui pemenuhan terhadap hal-hal di atas, maka diharapkan institusi fakultas akan dapat memiliki daya saing di era global. Jadi sebuah lembaga pendidikan akan mampu bersaing atau tidak tergantung kepada seberapa pemenuhan kualifikasi komponen-komponen di atas dapat dipenuhi.

Terakhir, konsep "critical mass" mungkin perlu diterapkan. Bilamana terjadi kejenuhan yang sangat kritis diperlukan a bunch of changes dalam fakultas. Dengan demikian teori sibernetik di sini diperlukan yaitu bagaimana melihat feedback dan keterkaitan antarkomponen yang saling mendukung. 


\section{TRANSFORMASI FAKULTAS FAVORIT}

Kondisi perguruan tinggi dengan fakultas-fakultasnya dewasa ini menunjukkan gejala ke arah keterpurukan tanpa konsep pengembangan yang jelas. Cenderung hanya sekedar dijadikan instrumen mobilitas vertikal masyarakat dalam pengertian yang sederhana, misalnya untuk mendapatkan gelar atau ijazah, lapangan pekerjaan yang mendatangkan finansial yang tinggi. Akibatnya, keberadaan fakultas yang seharusnya menjadi bagian terpenting untuk menggerakkan seluruh aktivitas perguruan tinggi menjadi lemah. Menyadari akan kenyataan, pandangan, pemikiran dan persoalan tersebut di atas, maka diperlukan keberanian untuk melakukan transformasi fakultas dengan mengadakan redefinisi, reorientasi, restrukturisasi secara menyeluruh dan mendasar terhadap pengembangan fakultas ke depan secara berkesinambungan.

Alasan utama dilakukannya proses transformasi fakultas adalah:17

1. Kebutuhan akan perluasan daya tampung yang dapat menjawab pemerataan pendidikan tinggi. Kenyataan menunjukkan bahwa jumlah mahasiswa perguruan tinggi di Indonesia merupakan jumlah yang paling rendah di ASEAN, sedangkan jumlah penduduknya terbesar.

2. Link and match antara program pendidikan dengan jenis dan program kerja yang terbuka baik secara langsung maupun tidak langsung.

3. Perguruan tinggi dengan fakultas-fakultasnya merupakan sebuah sistem yang diharapkan sebagai penghasil SDM yang berkualitas.

4. Mutu lulusan yang tinggi yang dibarengi dengan jenis program atau kemampuan yang bervariasi akan memberikan fleksibilitas eksternal yang tinggi sesuai dengan pasar kerja yang berkembang pesat.

5. Efisiensi adalah seberapa besar sumber daya yang digunakan untuk suatu hasil yang diinginkan, atau bagaimana rasio antara masukan dan keluaran. Dalam hal ini, perguruan tinggi dan fakultasnya dianggap efisien dan produktif, apabila sumber daya dan dana tersedia dengan sejumlah mahasiswa melalui proses pendidikan yang semakin besar.

Transformasi yang dimaksud untuk menjadikan fakultas sebagai fakultas yang bermutu harus dengan mengedepankan prinsip continous improvement. Hal ini secara umum dapat dilakukan dengan menerapkan prinsip manajemen yang diperkenalkan oleh Edwards Deming di Jepang tahun 1950.18

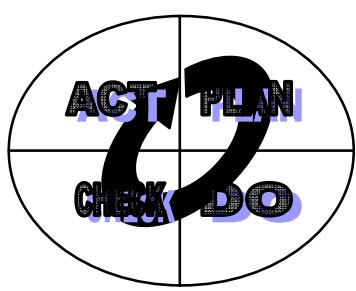


Konsep perubahan dengan PDCA tersebut di atas merupakan sebuah siklus dan dilakukan dengan menekankan pada perbaikan-perbaikan berkelanjutan (continous improvement) dan setiap yang dikerjakan selalu diawali dengan perencanaan, dan perencanaan tersebut diilhami dengan hasil yang telah dicapai sebelumnya sesuai dengan standar (benchmarking) yang sudah ditetapkan sebelumnya, sehingga ada perbaikan-perbaikan untuk implementasi rencana berikutnya. Sedangkan secara khusus transformasi fakultas ini dapat dilakukan dengan mengikuti pola di bawah:19

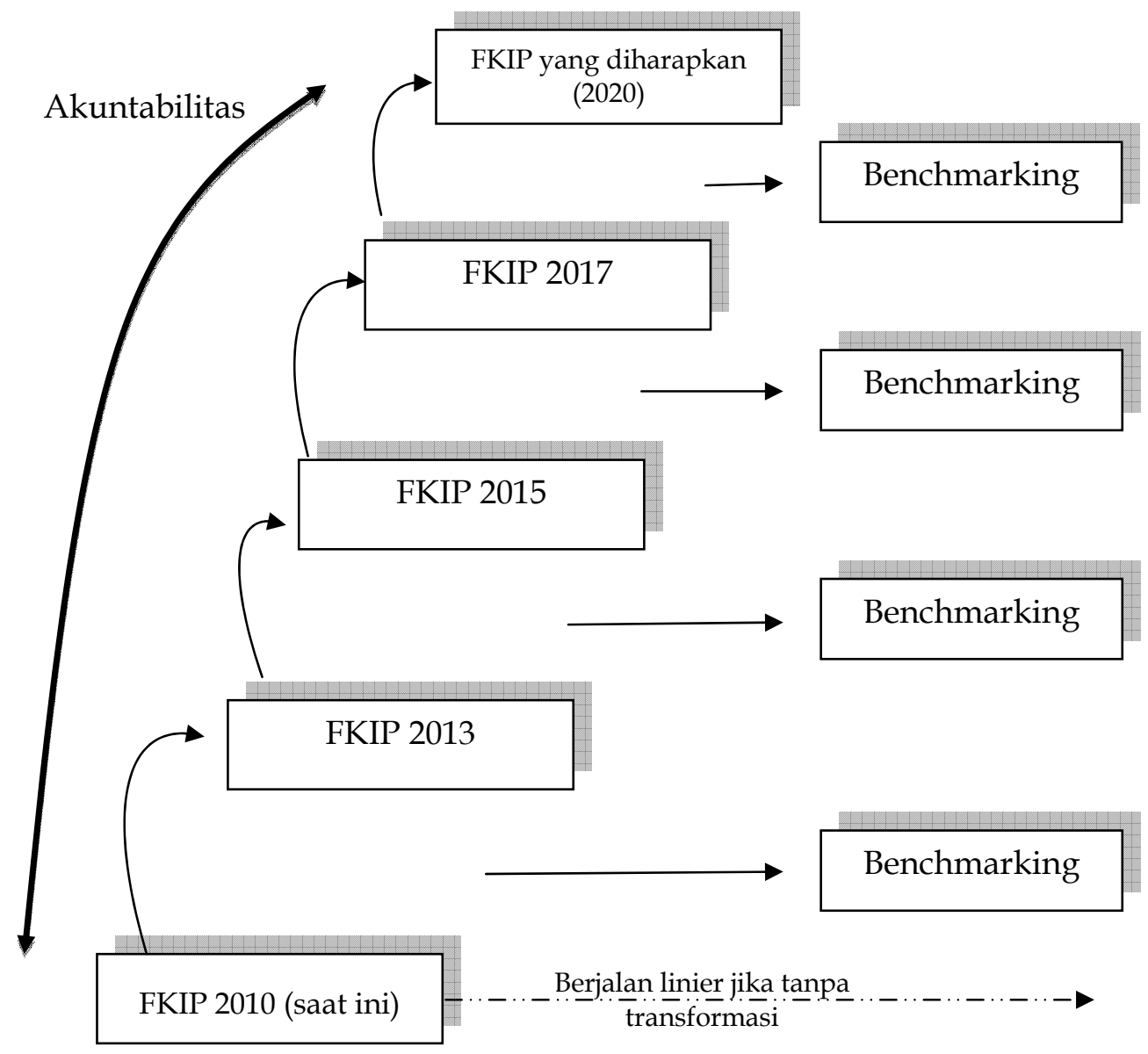

Bila bagan di atas jika dipadukan dengan konsep PDCA Deming maka akan menghasilkan tahapan sebagai berikut: 


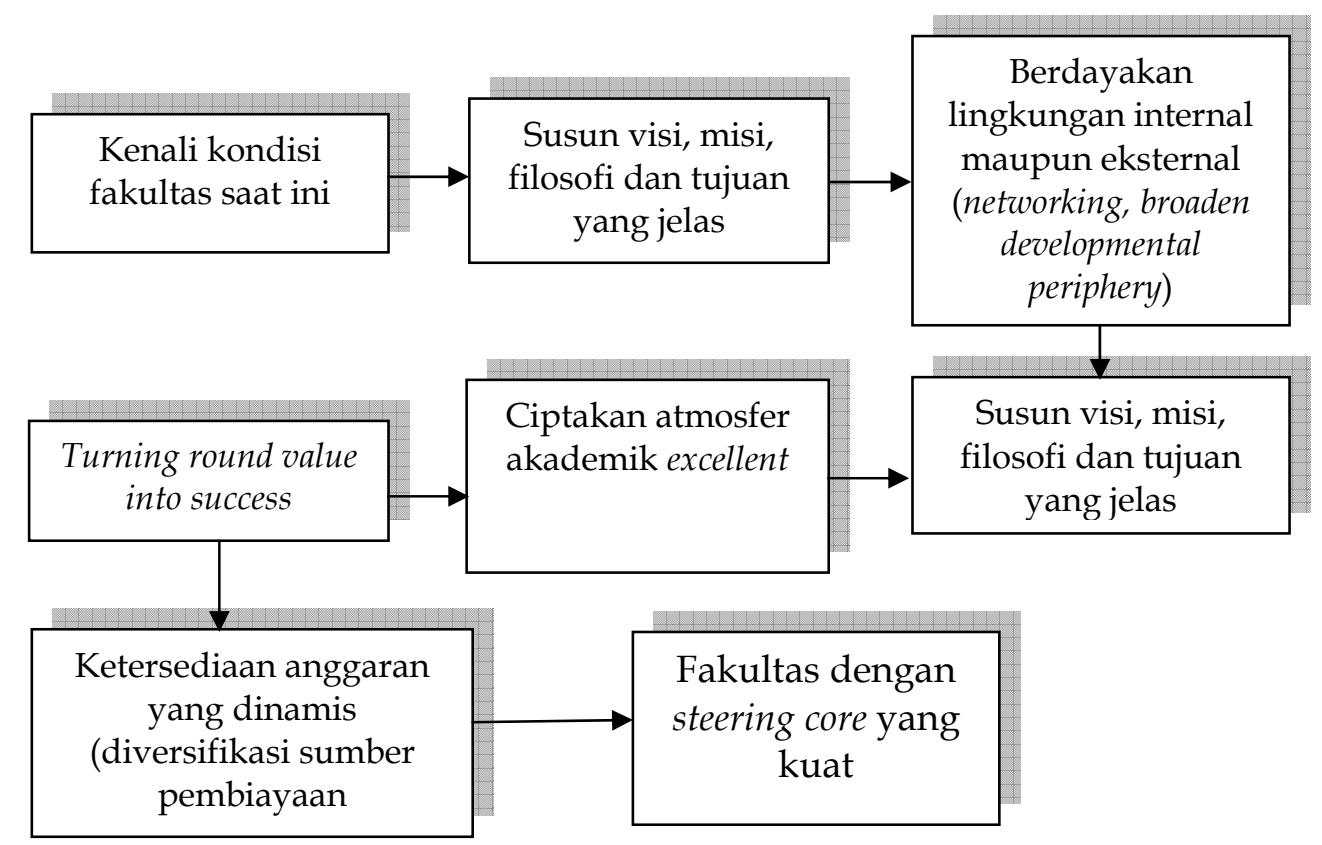

Salah satu ide yang bisa disiapkan oleh universitas yang ingin menjadikan fakultasnya menjadi fakultas favorit adalah menjadikan dirinya sebagai "Fakultas masa depan". Fakultas masa depan merupakan fakultas yang terdiri dari jurusan-jurusan favorit yang berkualitas dan mampu menjawab tantangan globalisasi dengan menyiapkan diri untuk menghadapi situasi kebutuhan bangsa di masa depan. The Future Faculty memberikan solusi bagi permasalahan-permasalahan yang ada saat ini dari level fakultas. Untuk itu terlebih dahulu harus ditetapkan kriteria fakultas yang diinginkan, meliputi:

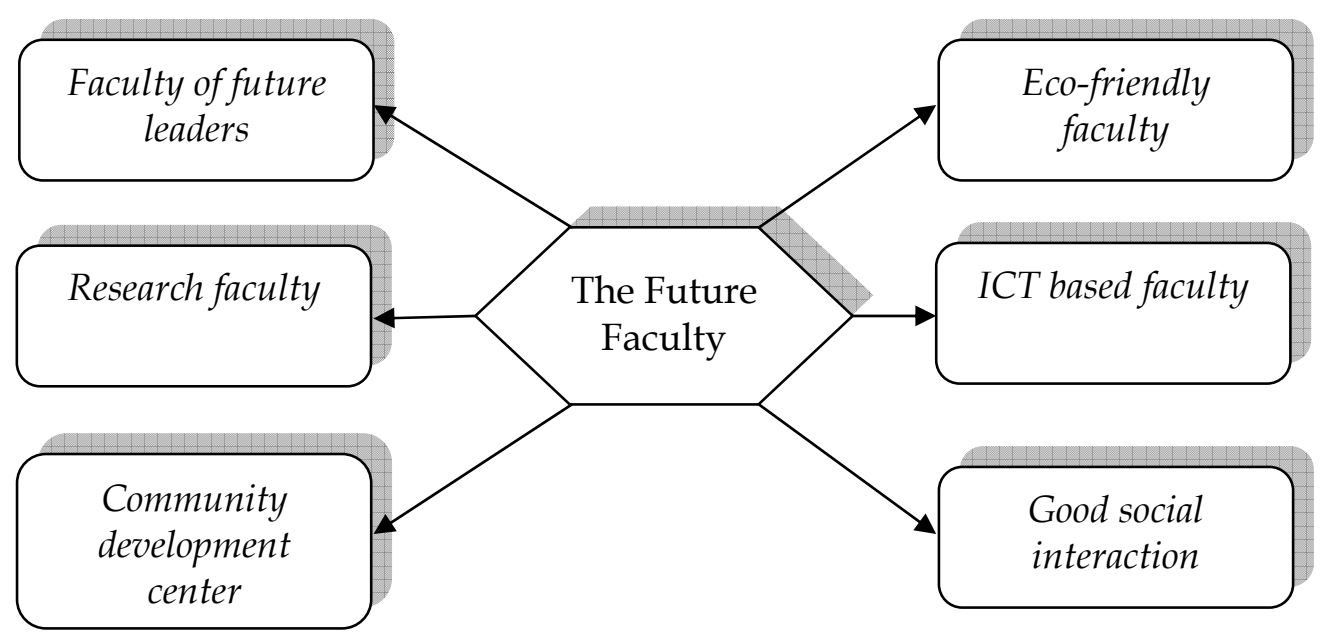


Langkah nyata yang dapat dilakukan oleh fakultas dapat mempertimbangkan hal-hal berikut:

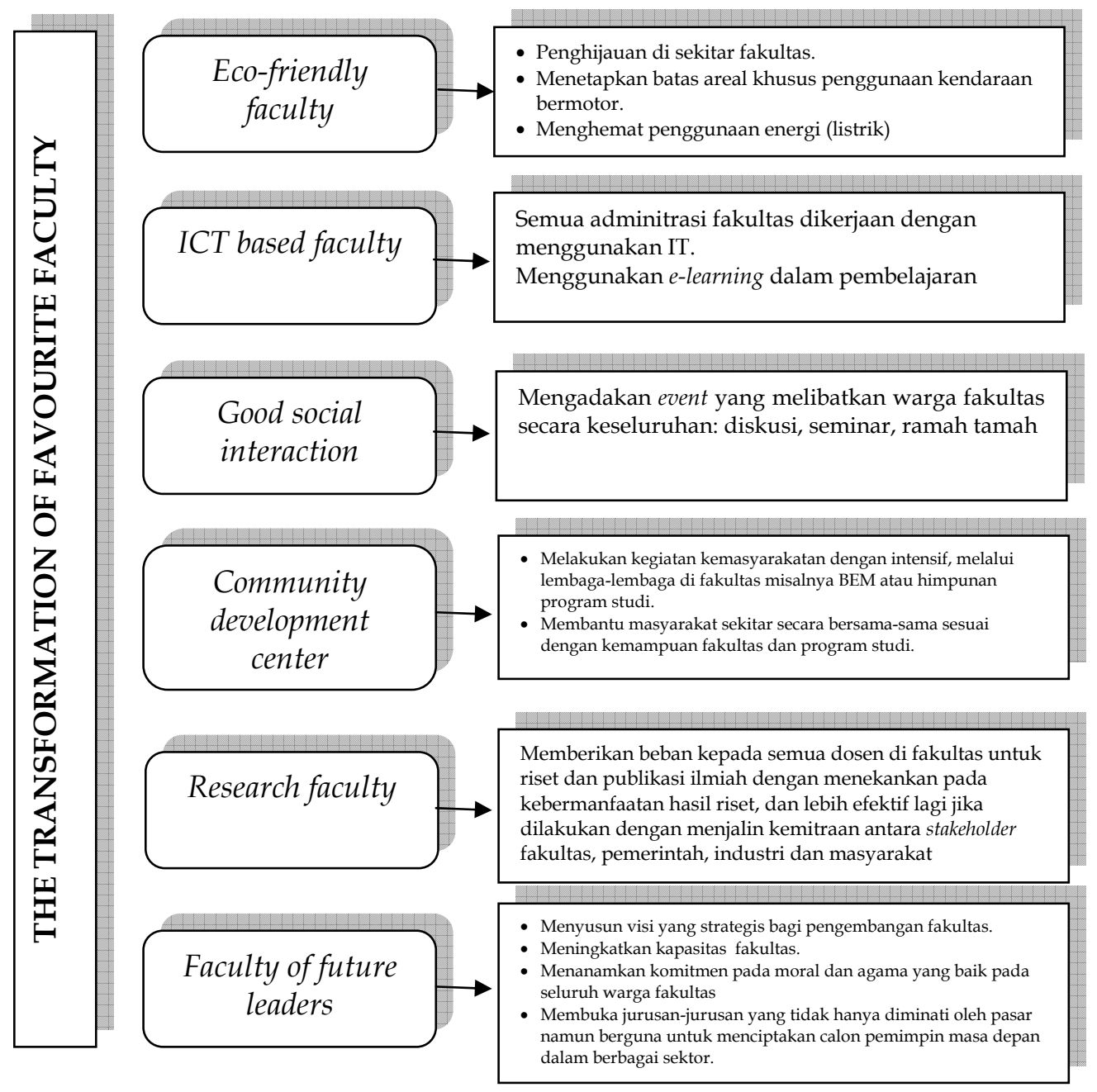

1. Eco-Friendly faculty, menjadikan fakultas sebagai fakultas yang ramah lingkungan dan hemat energi. Selama ini universitas beserta fakultasnya menjadi salah satu kontributor utama polusi di kota. Ke depan diusahakan agar menjadi teladan pertama dalam permasalaan lingkungan dan energi.

2. ICT Based faculty, Information and Communication Technology (ICT) akan terus menjadi teknologi yang berkembang pesat di masa depan. Fakultas harus segera tanggap menghadapi hal ini, jangan sampai "ketinggalan jaman". 
3. Interaksi sosial warga kampus, saat ini gap (kesenjangan) antar masyarakat semakin terlihat. Menurut saya, salah satu kriteria plus yang perlu dimiliki perguruan tinggi terbaik ialah adanya hubungan yang baik antara dosen, karyawan, mahasiswa, serta masyarakat.

4. Fakultas sebagai Community Development Center (CDC), peran fakultas di masa depan sebagai pusat pengembangan komunitas di masyarakat sekitar perlu ditingkatkan.

5. Research University, melakukan kegiatan riset (penelitian) merupakan sebuah keharusan bagi PT sesuai tridharma perguruan tinggi. Fakultas favorit sudah selayaknya memiliki banyak hasil riset dan publikasi.

6. Faculty of Future Leaders, menjadikan fakultas dengan fungsi utama sebuah perguruan tinggi untuk mencetak alumninya yang berkualitas, tak hanya sebagai "buruh" industri, namun juga sebagai calon pemimpin bangsa.

\section{KESIMPULAN}

Melihat fakta yang ada saat ini, sudah bukan saatnya lagi fakultas berjalan linear mengikuti struktur yang ada dan terbukti tidak menguntungkan. Fakultas perlu berbenah agar dapat meraih impiannya bahkan mengejar ketertinggalannya. Setidaknya fakultas dapat segera bercermin dan sesekali moving boders (melangkah sedikit keluar dari jalur yang ada) yang tentu saja jalur yang logis, potensial, dan logis. Berikut simpulan dari paparan pada bagian sebelumnya:

1. Pengelolaan fakultas setidaknya mencakup pemenuhan Kriteria Tingkat Keterlibatan Fakultas, melaksanakan Perubahan, berurusan dengan perubahan dan resistensi terhadap perubahan.

2. Pembiayaan fakultas menuntut kehati-hatian dan kecerdasan dalam pengelolaannya mengingat dukungan dana dari pemerintah untuk perguruan tinggi semakin kecil. Untuk itu fakultas perlu: Menetapkan Prioritas, memahami kekuatan dan kelemahan program, pengaturan internal dengan perguruan tinggi lain dan melihat perubahan kebutuhan masyarakat, membaca peluang bagi siswa dan permintaan mahasiswa.

3. Fakultas yang dikelola dengan baik hendaknya mampu menjalin hubungan internal dan eksternal yang harmonis. Hubungan tersebut hendaknya dijaga dan dikembangkan sehingga berimplikasi positif bagi input, proses, produk, output dan outcome fakultas sesuai dengan tujuan yang telah ditetapkannya.

4. Peran dekan dalam pengelolaan fakultas sangatlah penting mengingat dekan adalah orang nomor satu dalam fakultas. Dekan sangat perlu 
berperan maksimal dalam menciptakan suasana kondusif dalam fakultas yang dipimpinnya, menyentuh mahasiswa sesuai dengan kebutuhannya, dan menjaring hubungan dengan pihak lain (di dalam maupun diluar fakultas) sehingga tercipta image fakultas yang bersahaja.

5. Terdapat setidaknya lima aspek yang dapat ditempuh dekan dalam keinginannya menciptakan sebuah fakultas yang kuat dan pada gilirannya akan memberikan kontribusi pada universitas yang hebat yaitu penguatan steering core, memperluas jaringan periphery, memperkuat komponen inti (resources) dalam bentuk apapun di dalam fakultas, diversified funding base, dan semampunya menciptakan kultur enterpreneur.

6. Tugas yang demikian kompleks dapat dimainkan seorang dekan bilamana ia mampu menempatkan dirinya baik sebagai the dove, the dragon maupun the diplomat. Jika tidak demikian, maka itulah dekan yang juga disebut "penunggu fakultas."

Tulisan sederhana ini diharapkan dapat memberikan pemahaman yang cukup tentang peran fakultas dan dekan dalam pengelolaan fakultas yang kuat. Untuk itu saya berpikir semua pihak dapat mempertimbangkan empat aspek berikut:

1. Keberadaan fakultas pada sebuah Perguruan Tinggi merupakan ujung tombak bagi kualitas pendidikan yang dilaksanakannya. Untuk itu diharapkan agar setiap universitas memiliki dekan-dekan yang brilian, yaitu figur yang memahami fakultas dengan baik, memiliki komitmen tinggi untuk melejitkan fakultas, memiliki jiwa enterpreneur, mampu berinovasi dan berimprovisasi dalam mengembangkan fakultas yang diamanahkan kepadanya. Dekan yang mampu menempatkan dirinya dalam peran sebagai merpati perdamaian, sang naga pendobrak yang kuat dan diplomat yang arif dan bijaksana.

2. Fakultas merupakan subsistem dari suprasistem universitas. Subsistem tersebut hendaknya disentuh secara maksimal dan diberikan otonomi yang cukup dalam mengelola dirinya, dipenuhi kebutuhan-kebutuhannya sehingga dapat berperan maksimal dalam mewujudkan impian akademiknya.

3. Pemerintah, dunia usaha dan dunia industri, masyarakat dan lembagalembaga lain yang peduli terhadap pendidikan hendaknya terus mendukung perjalanan fakultas sehingga mampu memecahkan masalahmasalah yang dihadapinya. Namun demikian, fakultas tidak mungkin hanya menunggu. Fakultas harus mencari, menemukan dan bermain di dalamnya sehingga mampu mengambil manfaat dari kemenangan permainan tersebut. Sejalan dengan itu, audit internal maupun eksternal 
yang sahih menjadi salah satu indikator kunci dalam memacu perkembangan fakultas yang lebih baik.

4. Sudah saatnya fakultas memiliki jiwa enterpreneur. Dianulirnya BHP bukan berarti tidak ada yang baik dari rencana besar tersebut. Hikmah yang bisa dipetik fakultas adalah bagaimana sebuah fakultas diberikan otonomi yang cukup agar dapat mengembangkan sayapnya mengatur income, proses, output dan bahkan outcome-nya sendiri. Untuk itu sudah saatnya mempertimbangkan lima aspek enterpreneurial sebuah fakultas yang sukses.

\section{CATATAN AKHIR}

1. Alan Tucker and Robert A. Bryan, The Academic Dean, Dove, Dragon and Diplomat, Second Edition, New York: Macmillan Publishing Company, 1991, h. 12.

2. Ibid. h. 9.

3. Undang-undang Nomor 20 Tahun 2003 tentang Sistem Pendidikan Nasional, Bagian Keempat pasal 19 s.d 25.

4. Peraturan Pemerintah Nomor 60 tahun 1999 tentang Perguruan Tinggi, pasal 30, 45 s.d 48.

5. Alan Tucker, op. cit. h. 218.

6. Clark B.R., Creating Enterpreneurial Universities: Organization Pathways of Transformation, Paris: Published for the IAU Pergamon Press, 1998, h. 27.

7. Bill Reading, The University in Ruins, Massachussets: Harvard University Press, 1999, h. 25.

8. http://sisfokampus.wordpress.com/ Perguruan Tinggi Di Antara Globalisasi dan Internasionalisasi diakses tanggal 20 Juli 2009, 23.51 Wib.

9. Clark B.R., op. cit., h. 26.

10. Alan Tucker dan Robert A. Bryan, op.cit., h. 15.

11. Alan Tucker, Chairing the Academic Development, Leadership Among Peers, Third Edition, New York: Macmillan Publishing Company, 1992, h. 29.

12. J.J.F Forest and Albatch, Internatioinal Handbook of Higher Education. Netherland: Published by Spinger, 2006, h. 47.

13. Indra Bastian, Privatisasi di Indonesia: Teori dan Implementasi, Jakarta: Salemba Empat, 2002, h. 78.

14. Vincent Gaspersz, Continuous Cost Reduction Through Lean Six Sigma Approach, Canada: Irvin Publishing Company, 2006, h. 123.

15. K. Peters, Down to the Core. Government Executive, May, 31(5), 1999, h. 156.

16. J.G. Dees, Enterprising Nonprofits, Harvard Business Review, January-February 1998, h. 37.

17. J.G. Dees, ibid.

18. David L. Goetsch, and Stanley B. Davis, Implementing Total Quality, Upper Saddle River, NJ: Prentice Hall, 1995, h. 67.

19. Michael Shattock, Managing Successfull Universities, Open University Pres: McGrow-Hill, 2005, 79. 


\section{DAFTAR PUSTAKA}

Bastian, Indra, Privatisasi di Indonesia: Teori dan Implementasi, Jakarta: Salemba Empat, 2002.

Clark, B.R., Creating Enterpreneurial Universities: Organization Pathways of Transformation, Paris: Published for the IAU Pergamon Press, 1998.

Dees, J.G., Enterprising Nonprofits, Harvard Business Review, January-February 1998.

Forest.J.J.F, and Albatch, International Handbook of Higher Education, Netherland: Published by Spinger, 2006.

Gaspersz, Vincent, Continuous Cost Reduction Through Lean Six Sigma Approach, Canada: Irvin Publishing Company, 2006.

Goetsch, David L. and Stanley B. Davis, Implementing Total Quality, Upper Saddle river, NJ: Prentice Hall, 1995.

http://sisfokampus.wordpress.com/ Perguruan Tinggi Di Antara Globalisasi dan Internasionalisasi, artikel Internet, diakses tanggal 20 Juli 2009, 23.51 Wib.

Peraturan Pemerintah Nomor 60 tahun 1999 tentang Perguruan Tinggi, pasal 30, 45 s.d 48.

Peters, K., Down to the Core, Government Executive, May, 31(5), 1999.

Reading, Bill, The University in Ruins, Massachussets: Harvard University Press, 1999.

Shattock, Michael, Managing Successfull Universities, Open University Pres: McGrow-Hill, 2005.

Tucker, Alan dan Robert A. Bryan, The Academic Dean, Dove, Dragon and Diplomat, Second Edition, New York: Macmillan Publishing Company, 1991.

Tucker, Alan, Chairing the Academic Development, Leadership Among Peers, Third Edition, New York: Macmillan Publishing Company, 1992.

Undang-undang Nomor 20 Tahun 2003 tentang Sistem Pendidikan Nasional, Bagian Keempat pasal 19 s.d 25. 